\title{
Patient-reported outcome measures for systemic lupus erythematosus clinical trials: a review of content validity, face validity and psychometric performance
}

Laura Holloway ${ }^{1 \dagger}$, Louise Humphrey ${ }^{2}$, Louise Heron ${ }^{1}$, Claire Pilling ${ }^{1}$, Helen Kitchen ${ }^{3 \dagger}$, Lise Højbjerre ${ }^{4}$, Martin Strandberg-Larsen ${ }^{4}$ and Brian Bekker Hansen ${ }^{4^{*+}}$

\begin{abstract}
Background: Despite overall progress in treatment of autoimmune diseases, patients with systemic lupus erythematosus (SLE) experience many inflammatory symptoms representing an unmet medical need. This study aimed to create a conceptual model of the humanistic and economic burden of SLE, and review the patient-reported outcomes (PROs) used to measure such concepts in SLE clinical trials.
\end{abstract}

Methods: A conceptual model for SLE was developed from structured review of published articles from 2007 to August 2013 identified from literature databases (MEDLINE, EMBASE, PsycINFO, EconLit) plus other sources (PROLabels, FDA/EMA websites, Clinicaltrials.gov). PROs targeting key symptoms/impacts were identified from the literature. They were reviewed in the context of available guidance and assessed for face and content validity and psychometric properties to determine appropriateness for use in SLE trials.

Results: The conceptual model identified fatigue, pain, cognition, daily activities, emotional well-being, physical/ social functioning and work productivity as key SLE concepts. Of the 68 articles reviewed, 38 reported PRO data. From these and the other sources, 15 PROs were selected for review, including SLE-specific health-related quality of life (HRQoL) measures $(n=5)$, work productivity $(n=1)$, and generic measures of fatigue $(n=3)$, pain $(n=2)$, depression $(n=2)$ and HRQoL $(n=2)$. The Functional Assessment of Chronic Illness Therapy - Fatigue Scale (FACIT-Fatigue), Brief Pain Inventory (BPI-SF) and LupusQoL demonstrated the strongest face validity, conceptual coverage and psychometric properties measuring key concepts in the conceptual model. All PROs reviewed, except for three Lupus-specific measures, lacked qualitative SLE patient involvement during development. The Hospital Anxiety and Depression Scale (HADS), Short Form [36 item] Health Survey version 2 (SF-36v2), EuroQoL 5-dimensions (EQ-5D-3L and EQ-5D-5L) and Work Productivity and Activity Impairment Questionnaire: Lupus (WPAl:Lupus) showed suitability for SLE economic models.

Conclusions: Based on the identification of key symptoms and impacts of SLE using a scientifically sound conceptual model, we conclude that SLE is a condition associated with high unmet need and considerable burden to patients. This review highlights the availability and need for disease-specific and generic patient-reported measures of relevant domains of disease signs and symptoms, HRQoL and work productivity, providing useful insight for SLE clinical trial design.

Keywords: Systemic lupus erythematosus, Patient-reported outcomes, Conceptual model, Fatigue, Health-related quality of life

\footnotetext{
* Correspondence: bbkh@novonordisk.com

${ }^{\dagger}$ Equal contributors

${ }^{4}$ Novo Nordisk A/S, Novo Allé 1, 2880 Bagsvaerd, Denmark

Full list of author information is available at the end of the article
} 


\section{Background}

Systemic lupus erythematosus (SLE) is a heterogeneous, inflammatory, multisystem autoimmune disease. Estimates of overall prevalence rates (per 100,000) vary worldwide, ranging from 4-45 in Asia-Pacific countries [1], to 52-150 in the USA $[2,3]$. The prevalence of SLE is greater in nonwhite racial groups [2] and the disease affects women more frequently than men [4]. SLE is associated with a substantial economic burden, with direct costs per patient-year ranging from $\$ 3,735$ to $\$ 14,410$ [5].

There is a large variation in SLE associated symptoms and the condition is often complicated by flares (exacerbations) of varying severity and subsequent remissions [6]. A recent international consensus working group defined a flare as "a measurable increase in disease activity in one or more organ systems involving new or worse clinical signs and symptoms and/or laboratory measurements" [7].

Patients with active SLE experience musculoskeletal and mucocutaneous manifestations, including joint pain and swelling, skin rash and fatigue [8]. Frequently affected joints include the fingers, hands, wrists and knees, with some patients developing secondary osteoarthritis [8]. In addition to joint inflammation, internal organ involvement can be of greater concern when considering patients' prognosis, with SLE often affecting the heart, lungs, blood vessels, liver, kidneys and nervous system $[8,9]$. Overall these symptoms and manifestations can contribute to a substantially reduced health-related quality of life (HRQoL) [10].

It is not possible to assess many of the symptoms and treatment effects associated with SLE using objective clinical measures alone. Regulatory bodies and healthcare decision makers recognise the importance of also capturing the patient perspective in clinical trials by using validated and reliable patient-reported outcome (PRO) measures [11-13]. The U.S. Food and Drug Administration (FDA) and the European Medicines Agency (EMA) have released guidance which highlights the importance of measuring fatigue in clinical trials in SLE [14,15] (although the FDA does not necessarily consider existing measures of fatigue to be adequate), and the EMA also strongly recommends the consideration of the impact of SLE on patients' HRQoL [15]. In 1999 an Outcome Measures in Rheumatology group (OMERACT) performed a review of outcome measures that have been used in SLE trials and made recommendations regarding the most important domains to assess, and the most appropriate instruments to do so $[16,17]$. However, as it has been a number of years since that review, there is value in a more up to date review of the literature which identifies relevant concepts for measurement and the adequacy of existing measures to assess those concepts. In particular, no disease-specific measures of health status or disability were identified at that time. An understanding of the symptoms and their impact on patients' daily lives, the economic burden and the PRO measures available, will help researchers and clinicians evaluate the efficacy and impact of interventions.

The objectives of this research were twofold. The objective of the first stage of this research was to review and describe the symptoms and impact concepts of SLE from the patient's perspective by means of a conceptual model. This included an overview of the economic burden of SLE. Based on development of the conceptual model, the objective was then to review existing PRO measures for suitability in clinical trials of SLE, in terms of their content validity, face validity and psychometric properties.

\section{Methods}

A structured literature review was conducted to establish the humanistic and economic burden with respect to the key symptoms and their impact, and the PROs available to measure these. Methods were in line with recognised international guidelines for the conduct and reporting of literature reviews $[18,19]$. The findings from the literature review informed the development of a conceptual model that was used to assess whether the selected PRO measures target the key symptoms and impacts of SLE in accordance with the EMA and FDA PRO guidance $[11,12]$.

\section{Data sources and searches}

Literature searches were conducted in MEDLINE, EM BASE, PsycINFO and EconLit, limited to humans, English language and articles published between 2007 and 2013. The search was conducted on 1st August 2013.

\section{Inclusion and exclusion criteria}

Journal articles (excluding conference abstracts, dissertations and book chapters) containing the keywords in the title and/or abstract were included. Articles with an SLE-related clinical search term and at least one of the humanistic or economic search terms were selected.

Search terms included SLE clinical terms (systemic lupus erythematosus, SLE, lupus nephritis, LN) plus outcomes research terms (health-related quality of life, quality of life, patient burden, patient impact, burden of illness, symptom, activities of daily living, patient reported outcome, patient related outcome, PRO, questionnaire, fatigue, physical function, emotion, mood) or economic terms (cost OR cost utility, cost of illness, healthcare cost, economic burden, economic impact, resource use, hospitalisation, productivity, expenditure, direct costs, indirect costs, economic, cost minimisation, burden of illness, cost effectiveness).

\section{Screening process and data extraction}

Two researchers screened and checked all the abstracts for eligibility and suitability in line with the Centre for 
Reviews and Dissemination guidance [19]. Articles selected for review were based on consensus opinion. Any disagreement in the selection of articles was resolved by the lead researcher who performed a final, independent review of titles and abstracts. The selected articles were categorised into qualitative studies reporting burden from the patient perspective and articles reporting humanistic and economic burden data. Literature documenting quantitative methods was also reviewed to further understand the symptoms of SLE, the impact on patients' HRQoL and to support the conceptual model. Study characteristics from the selected articles were extracted.

\section{Development of the conceptual model of systemic lupus erythematosus}

A conceptual model of the humanistic and economic burden of SLE was developed on the basis of the review of qualitative studies [20]. A conceptual model can help identify themes, describe the patient burden concepts and their interrelationships and provide the rationale for PRO measures of interest [11,21]. For the purposes of this study, a conceptual model for SLE provided the theoretical basis for the review and evaluation of the content validity of the selected PRO measures. The model was then compared with an existing SLE conceptual model developed by Gallop et al. [22] in 2012.

\section{Review of the patient-reported outcome measures for systemic lupus erythematosus}

A subset of the PRO measures identified in the literature search were selected for in-depth review. Selection of instruments for in-depth review was based on likelihood of meeting the FDA guidance and relevance of conceptual coverage, based on review of the abstract and initial review of the PRO. Searches of PROQOLID, PROLabels, FDA/EMA websites, Clinicaltrials.gov and reimbursement agencies' websites (e.g. National Institute of Health and Care Excellence (NICE, UK) and the Institute for Quality and Efficiency in Healthcare (IQWIG, Germany)) were conducted when either no relevant PRO that measured a key concept could be identified from the literature, or when expert opinion suggested the use of alternative PROs. Other PRO measures were only included in the review if the PRO was developed or validated in patients with SLE, had been previously used in a SLE population and/or if there was evidence of normative data available for comparison. Articles in the literature search that reported PRO data were categorised according to the type of PRO measure included in each study. The categories were largely based on the key concepts identified in the conceptual model.

Each PRO was reviewed for appropriateness for clinical trials in patients with SLE in terms of content validity, face validity and psychometric properties, in line with regulatory guidance for the evaluation of PRO measures $[11,12]$. Content validity was assessed by the coverage level of the concepts within the conceptual model $[11,12]$. The face validity of each PRO measure was determined by the acceptability and appropriateness of item wording, recall period and response options to patients with SLE. The level of qualitative research involved in developing each PRO was also assessed, acknowledging the value of input from the target patient population. The psychometric properties (validity, reliability and ability to detect change) of each PRO for an SLE population were also assessed in line with FDA regulatory guidance for the development and validation of PROs [11,23].

\section{Results}

\section{Findings from the literature search}

The literature search identified a total of 1,754 publications. Of these, 687 articles met the inclusion criteria and the full articles were retrieved. A review of these identified 30 articles containing data on the economic burden of SLE. These were used to describe the economic burden in the conceptual model. The remaining 38 articles were related to patient-reported symptoms, impacts and burden in patients with SLE.

\section{Conceptual model of systemic lupus erythematosus}

Of the 38 articles that included patient-reported data, six were qualitative articles [22,24-28] and 32 were quantitative articles. The resulting conceptual model shows the symptoms and impacts identified as key concepts related to SLE (Figure 1).

Fatigue and pain were identified as two of the most important and frequent symptoms for patients with SLE [24-26,29-32] (Figure 1). Specifically, patients describe mental and physical symptoms of fatigue including impacts on social life [24], emotional wellbeing [24,33], physical functioning [22,24], sleep [31,34-36] and the ability to complete daily tasks and leisure activities $[27,28]$. Important cognitive symptoms include being "unable to think clearly" [22] and memory loss [22]. Other SLE symptoms include skin rash $[27,37]$, weight gain $[24,27]$ and hair loss [25,27].

Symptoms impact all areas of HRQoL, with detrimental consequences observed in the physical, emotional and social functioning of SLE patients, as well as in their working life (Figure 1). In terms of the impact on emotional wellbeing, patients with SLE frequently feel sad, depressed, angry and demoralised [22,24,25,30,37,38]. In particular, patients feel embarrassed [24,25,39] or selfconscious, or they lack self-esteem, primarily because of the change in their appearance (such as hair loss and skin manifestations) [22,26]. Patients fear their disease worsening, and experience anxiety or stress related to the symptoms and the unpredictability of SLE [27,30,37,38]. Many also experience feelings of frustration and a lack of 1) 


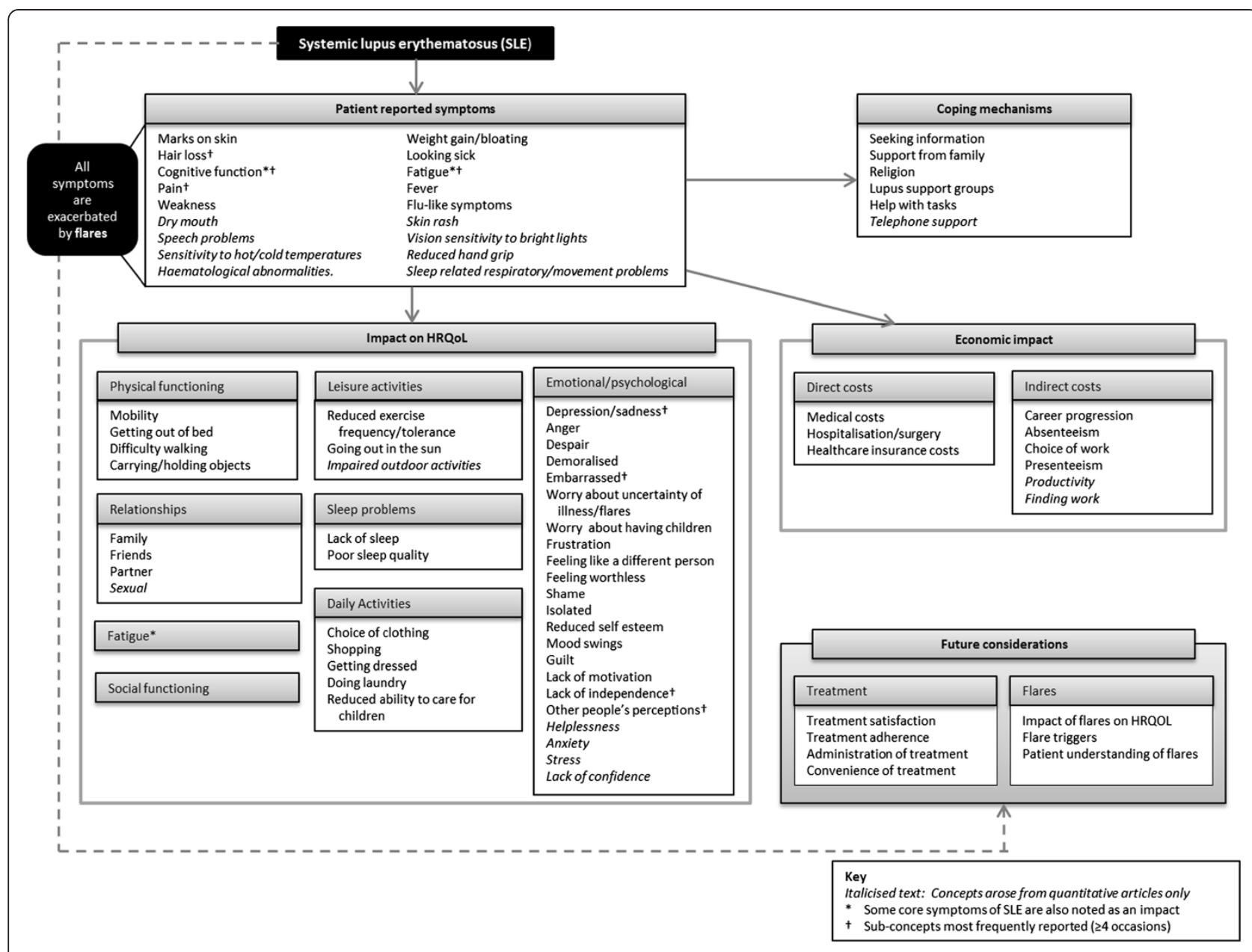

Figure 1 Systemic lupus erythematosus conceptual model.

confidence, 2) independence, 3) control over one's life and 4) belonging [40].

SLE has a significant negative impact on patients' physical functioning, such as walking difficulty and other mobility problems [10,22,26,41] (Figure 1). This affects various daily activities including opening jars and moving heavy objects [41], shopping [22], doing laundry [26], getting dressed [26] and caring for their children [24,26]. Wider impacts on social functioning and working life are also reported $[29,40]$. Specifically, patients have difficulty maintaining family and sexual relationships $[24,26,37]$. SLE also impacts negatively on patients' career progression [25], absence from work [22], difficulty concentrating at work or study $[22,26,32]$ and their choice of work $[26,27]$.

The conceptual model presented in this paper suggests that patients use various coping mechanisms for the unpredictability of flares, including 1) seeking and using information, 2) seeking emotional and practical help via the internet, 3) receiving support from hospital meetings, 4) receiving support from family, 5) attending lupus support groups and 6) religious practice [24,26,27] (Figure 1).
The conceptual model also includes concepts such as treatment satisfaction, adherence and the impact of flares in a 'future considerations' box. There was a lack of evidence pertaining to these concepts in the currently available literature.

The conceptual model also demonstrates the economic burden of disease, in particular the high medical costs associated with SLE compared to other chronic diseases [42]. Substantial levels of inpatient care, medication/prescriptions and visits to healthcare professionals (HCP), which are all increased by 'flares', are the main drivers of direct costs in the treatment of SLE [43]. The conceptual model also shows that SLE is associated with high indirect costs due to lost productivity [5] resulting from unemployment and absenteeism, [44], with 'in-flare' patients with SLE having increased frequency and duration of time off work $[45,46]$.

A comparison between this conceptual model and the model developed by Gallop et al. [22] suggests similarities, although our model provides a broader perspective on the impact of SLE. There is alignment between the 
models on symptoms such as pain, fatigue, skin rash and hair loss. Impact on work/employment, impact on daily life/daily activities, lack of independence and emotional wellbeing are also presented in both models. In terms of differences, Gallop's model [22] viewed impacts on social, family and leisure activities as one concept; however, the present literature review and model identified these as separate concepts. The emotional impact is conceptualised as depression or frustration in Gallop's model [22], whilst a broader range of emotions associated with SLE (including worry, anger, embarrassment and shame in addition to depression and frustration) were identified in the literature. Unlike the model presented in this paper, impacts on physical functioning, relationships, sleep, worry about the ability to conceive/have children, the impact of others' perceptions and the personal and broader economic burden are not shown in Gallop's model. Whilst fatigue is noted as a symptom in both models, the model presented in this paper also conceptualises fatigue as an impact of SLE. Gallop et al. [22] include appearance and cognition concepts as impacts of SLE but these are captured as symptoms in the present model. Gallop et al. [22] also recognise the different triggers that may lead to the onset or worsening of symptoms in their conceptual model; however these issues were not identified in the present literature review.

\section{Review of patient-reported outcomes measures}

A total of 23 PRO measures were identified from the articles reviewed. Of those, 15 measures targeted key concepts in the conceptual model and were therefore selected for in-depth review (Table 1). SLE-specific and generic PROs were categorised according to the concepts measured.

\section{Content validity - conceptual coverage}

An overview of the conceptual coverage of each PRO measure was performed to evaluate content validity (Table 2). Of all 15 PROs reviewed, only the diseasespecific LupusQoL, LupusPRO, L-QoL and SLEQOL have documented evidence for involvement of patients with SLE in concept elicitation and development of items $[50,52,54,55]$.

In terms of the SLE-specific and generic HRQoL instruments, the SF-36v2, LupusQoL and SLEQOL demonstrated a greater level of conceptual coverage, in terms of the variety and number of relevant SLE concepts measured, compared to the other four HRQoL instruments (Table 2).

All three fatigue PROs demonstrated similar levels of conceptual coverage for SLE, with each measuring fatigue and its impact on daily activities and social functioning (Table 2). The $M A F$ was the only fatigue-related $\mathrm{PRO}$ to measure the impact of fatigue on relationships (i.e. sexual activity or socialising with friends) and ability to work. Of the two pain-related PROs, the BPI-SF had superior conceptual coverage compared to the $M P Q$, measuring both pain symptoms and the impact of pain on a range of aspects of daily life.

As expected, both depression-related PROs were focussed on the emotional/psychological well-being impact, but the $B D I$ also measures fatigue ('tiredness'), patients' attitudes towards their appearance and impact on sleep and ability to work - concepts which are also relevant to SLE patients (Table 2). The WPAI:Lupus measures relevant SLE concepts such as ability to work, disability associated with lupus and the impact of lupus on activities of daily living such as housework and childcare.

\section{Face validity}

Of all the PRO measures reviewed, only the LupusQoL, LupusPRO and L-QoL had documented evidence of qualitative involvement of patients with SLE to evaluate the face and content validity through cognitive debriefing techniques (Table 3). The LupusPRO was pilot tested with SLE patients, though the face validity was not qualitatively assessed. Patient insights were used in the development of the $S L E Q O L$, although only by means of ranking items in order of importance; the face validity was not qualitatively assessed. A face validity review suggested that the instructions and item wording, recall period and response options for six PRO measures (L-QoL, SF-36v2, EQ-5D-3L, EQ-5D-5L, FACIT-Fatigue, HADS) appeared acceptable and appropriate for a SLE population and are in line with guidance for the use of PROs in clinical trials [11] (Table 3). The standard version of the SF-36v2 has a four week recall period, which is unlikely to be acceptable to regulators. However, the acute version, with a seven day recall period, is likely to be more acceptable. The item and instruction wording of each PRO measure was clear, free of clinical terminology and generally written in simple language. The response options of these six PROs are generally clear and appropriate for patients with SLE. Furthermore, the recall periods were appropriate for intended use of the measures with patients with SLE.

In contrast, the other nine PROs included features which may hinder understanding and completion of the items by patients (Table 3). Four PROs used vague and insufficiently defined (e.g. 'leisure and recreational activities' and 'fatigue' in the $M A F$ ) or complex terminology (e.g. 'lacerating' and "spatial" in the $M P Q$ ) in the items and instructions. The individual instructions provided for the WPAI:Lupus items increase the word count/length, which may be overwhelming for some patients.

The format of the response options for some PROs was inconsistent, which may cause confusion to patients (SLEQOL, MFI, MAF); some used complex terms such as 'excruciating' $(M P Q)$ or were lengthy and ambiguous $(B D I)$ (Table 3). 
Table 1 Patient-reported outcome measures reviewed

\begin{tabular}{|c|c|c|c|c|}
\hline Instrument & $\begin{array}{l}\text { Number } \\
\text { of items }\end{array}$ & Recall period & Response format & $\begin{array}{l}\text { Reference or rationale for inclusion } \\
\text { of PRO if not cited in the literature } \\
\text { search }\end{array}$ \\
\hline $\begin{array}{l}\text { Systemic Lupus Activity } \\
\text { Questionnaire (SLAQ) [47] }\end{array}$ & 28 & Last 3 months & $\begin{array}{l}\text { First } 27 \text { items have 4-point scale, ranging } \\
\text { from 'none' to 'severe'. Last item has a } \\
1-10 \text { numerical rating scale (NRS) }\end{array}$ & {$[47-49]$} \\
\hline LupusQoL [50] & 34 & Last 4 weeks & $\begin{array}{l}\text { 5-point scale ranging from 'never' to } \\
\text { 'all of the time' }\end{array}$ & {$[30,51]$} \\
\hline LupusPRO [52] & 43 & Last 4 weeks & $\begin{array}{l}\text { 5-point scale ranging from 'never' to } \\
\text { 'all of the time' }\end{array}$ & {$[52,53]$} \\
\hline L-QoL [40] & 25 & At the moment & Dichotomous 'true'/'not true' scale & {$[30,40,54]$} \\
\hline SLEQOL [55] & 40 & Last week & $\begin{array}{l}\text { All } 7 \text { point Likert scales, although scales } \\
\text { have different labels (i.e. 'not difficult at } \\
\text { all' to 'very difficult'; 'not at all' to } \\
\text { 'extremely troubled'; 'not at all' to } \\
\text { 'extremely often') }\end{array}$ & {$[30,54]$} \\
\hline $\begin{array}{l}\text { Short Form } 36 \text { version } 2 \\
\text { (SF-36v2) [56] }\end{array}$ & 36 & $\begin{array}{l}\text { Standard 4-week recall } \\
\text { or Acute 1-week recall } \\
\text { version. }\end{array}$ & $\begin{array}{l}\text { Varies dependent on scale [Yes/No and } \\
3,5 \text { and 6-point Likert scales]. }\end{array}$ & {$[30,47,49,54,57-63]$} \\
\hline $\begin{array}{l}\text { Euroqol } 5 \text { Domain (EQ-5D) } \\
\text { (3-Level and 5-Level) [64,65] }\end{array}$ & 6 & $\begin{array}{l}\text { Recall of 'today for } \\
\text { both } 3 L \text { and } 5 \\
L \text { version. }\end{array}$ & $\begin{array}{l}\text { 3-point scale on } 3 L \text { and } 5 \text {-point scale } \\
\text { on } 5 L \text { version, ranging from absence } \\
\text { to inability to perform activity or } \\
\text { extreme severity of symptom }\end{array}$ & $\begin{array}{l}\text { Previously used in patients with SLE, } \\
\text { and normative data exist for } \\
\text { comparison. EQ-5D is a measure used } \\
\text { to derive utilities }\end{array}$ \\
\hline $\begin{array}{l}\text { Functional Assessment of } \\
\text { Chronic Illness Therapy- } \\
\text { Fatigue Scale (FACIT- } \\
\text { Fatigue) [66] }\end{array}$ & 13 & Past 7 days & $\begin{array}{l}\text { 5-point scale ranging from 'not at } \\
\text { all' to 'very much'. }\end{array}$ & {$[54]$} \\
\hline $\begin{array}{l}\text { Multidimensional Fatigue } \\
\text { Inventory (MFI) [67] }\end{array}$ & 20 & Lately & $\begin{array}{l}\text { 5-level agreement scale from 'Yes, that } \\
\text { is true' to 'No, that is not true'. }\end{array}$ & [35] \\
\hline $\begin{array}{l}\text { Multidimensional Assessment } \\
\text { of Fatigue (MAF) [68] }\end{array}$ & 16 & Past week & $\begin{array}{l}1-10 \text { numerical rating scale ('not at } \\
\text { all' - 'a great deal) for items } 1-14 . \\
\text { Multiple-choice response for items } 15 \\
\text { and } 16 .\end{array}$ & [35] \\
\hline $\begin{array}{l}\text { McGill Pain Questionnaire } \\
\text { (MPQ) [69] }\end{array}$ & 20 & Present pain & $\begin{array}{l}\text { Mixed, ranging from 2-point to 6-point } \\
\text { scales }\end{array}$ & [70] \\
\hline $\begin{array}{l}\text { Brief Pain Inventory - Short } \\
\text { Form (BPI-SF) [71] }\end{array}$ & 15 & Last 24 hours & $\begin{array}{l}\text { Most items have an } 11 \text { point numerical } \\
\text { rating scale, ranging from } 0=\text { no pain } \\
\text { and } 10=\text { pain. One item has a binary } \\
\text { yes/no response and another ask } \\
\text { patients to shade a diagram to show } \\
\text { where they have pain. One item has a } \\
0 \%-100 \% \text { scale increasing in } 10 \% \\
\text { increments. }\end{array}$ & $\begin{array}{l}\text { Pain is a key symptom of SLE and the } \\
\text { BPI-SF has previously been used in a } \\
\text { SLE population }\end{array}$ \\
\hline $\begin{array}{l}\text { Beck Depression Inventory } \\
\text { (BDI) [72] }\end{array}$ & 21 & Not specified & $\begin{array}{l}\text { 4-point scale with detailed wording } \\
\text { provided for each response. }\end{array}$ & $\begin{array}{l}\text { Depression is a key concept in SLE. The } \\
\text { BDI has been used previously with } \\
\text { patients with SLE, and normative data } \\
\text { exist for comparison }\end{array}$ \\
\hline $\begin{array}{l}\text { Hospital Anxiety and } \\
\text { Depression Scale } \\
\text { (HADS) [73] }\end{array}$ & 14 & Past week & 4-point scale & $\begin{array}{l}\text { Depression is a key concept in SLE. The } \\
\text { HADS has been used previously with } \\
\text { patients with SLE and normative data } \\
\text { exist for comparison }\end{array}$ \\
\hline $\begin{array}{l}\text { Work Productivity and } \\
\text { Activity Impairment } \\
\text { Questionnaire: Lupus } \\
\text { (WPAl:Lupus) [74] }\end{array}$ & 6 & Past 7 days & Yes/No \& NRS & $\begin{array}{l}\text { Absenteeism and presenteeism is a } \\
\text { major burden for patients with SLE. The } \\
\text { WPAl:Lupus has been used previously } \\
\text { in patients with SLE and normative } \\
\text { data exist for comparison. }\end{array}$ \\
\hline
\end{tabular}

\section{Psychometric properties}

The LupusQoL, EQ-5D and the FACIT-Fatigue demonstrated the strongest psychometric properties in an SLE population [47,50,75-77] (Table 4). Psychometric validation of the $S L A Q$, LupusPRO and SF-36v2 has also been conducted in SLE $[47,52,76,78,79]$. None of the other 
Table 2 Content validity of patient-reported outcome measure

\begin{tabular}{|c|c|c|c|c|c|c|c|c|c|c|c|c|c|c|c|}
\hline \multirow{2}{*}{$\begin{array}{l}\text { Concept identified in } \\
\text { literature review }\end{array}$} & \multicolumn{5}{|c|}{ SLE-specific HRQoL } & \multicolumn{2}{|c|}{ Generic HRQoL } & \multicolumn{3}{|l|}{ Fatigue } & \multicolumn{2}{|l|}{ Pain } & \multicolumn{2}{|c|}{ Depression } & \multirow{2}{*}{$\begin{array}{l}\text { Work } \\
\text { WPAl: } \\
\text { Lupus }\end{array}$} \\
\hline & $\overline{S L A Q}$ & LupusQoL $^{\$}$ & LupusPRO $\$$ & L-QoL & $\overline{\text { SLEQOL }}$ & SF-36v2 & EQ-5D" & FACIT-Fatigue & MFI & MAF & $\overline{M P Q}$ & $\overline{\text { BPI-SF }}$ & $\overline{\mathrm{BDI}}$ & $\overline{\text { HADS }}$ & \\
\hline \multicolumn{16}{|l|}{$\begin{array}{l}\text { Disease-defining signs } \\
\text { and symptoms }\end{array}$} \\
\hline Marks on skin & $\checkmark$ & & & & & & & & & & & & & & \\
\hline Weight gain/bloating & $\checkmark$ & $\checkmark$ & & & & & & & & & & & & & \\
\hline Hair loss & $\checkmark$ & $\checkmark$ & $\checkmark$ & & & & & & & & & & & & \\
\hline \multicolumn{16}{|l|}{ Looking sick } \\
\hline $\begin{array}{l}\text { Reduced cognitive } \\
\text { function }\end{array}$ & $\checkmark$ & $\checkmark$ & $\checkmark$ & & $\checkmark$ & & & & $\checkmark$ & & & & & & \\
\hline Fatigue & $\checkmark$ & $\checkmark$ & $\checkmark$ & $\checkmark$ & $\checkmark$ & $\checkmark$ & & $\mathfrak{V}^{*}$ & $\sqrt{ }^{*}$ & $\checkmark^{*}$ & & & $\checkmark$ & & \\
\hline Pain & $\checkmark$ & & $\checkmark$ & & $\checkmark$ & $\checkmark$ & $\checkmark$ & & & & $\checkmark$ & $\checkmark$ & & & \\
\hline Fever & $\checkmark$ & & & & & & & & & & & & & & \\
\hline Weakness & & & & & & $\checkmark$ & & $\mathfrak{V}^{*}$ & $\checkmark^{*}$ & & & & & & \\
\hline \multicolumn{16}{|l|}{ Flu-like symptoms } \\
\hline \multicolumn{16}{|l|}{ Impacts } \\
\hline Physical functioning & & $\checkmark$ & $\checkmark$ & & $\checkmark$ & $\checkmark$ & $\checkmark$ & & $\sqrt{ }^{*}$ & $\mathfrak{S}^{*}$ & & $\mathfrak{S}^{*}$ & & & \\
\hline Daily activities & & $\checkmark$ & $\checkmark$ & $\checkmark$ & $\checkmark$ & $\checkmark$ & $\checkmark$ & $\sqrt{ }^{*}$ & $\checkmark^{*}$ & $\checkmark^{*}$ & & $\mathfrak{S}^{*}$ & & & $\checkmark$ \\
\hline Sleep problems & & $\checkmark$ & & & & $\checkmark$ & & $\checkmark^{*}$ & $\boldsymbol{V}^{*}(p)$ & & & $\checkmark^{*}$ & & & \\
\hline $\begin{array}{l}\text { Emotional/ } \\
\text { Psychological }\end{array}$ & $\checkmark$ & $\checkmark$ & $\checkmark$ & $\checkmark$ & $\checkmark$ & $\checkmark$ & $\checkmark$ & $\checkmark^{*}$ & & $\boldsymbol{J}^{*}(p)$ & & $\mathfrak{S}^{*}$ & $\checkmark$ & $\checkmark$ & \\
\hline Social functioning & & $\checkmark$ & & $\checkmark$ & $\checkmark$ & $\checkmark$ & & $\checkmark^{*}$ & $\mathfrak{J}^{*}(p)$ & $\checkmark^{*}$ & & & & & \\
\hline Leisure activities & & $\checkmark$ & & & $\checkmark$ & $\checkmark$ & & & $\sqrt{ }^{*}$ & $\checkmark^{*}$ & & & & & \\
\hline Relationships & & $\checkmark$ & & $\checkmark$ & & $\checkmark$ & & & & $\checkmark(p)$ & & $\checkmark^{*}$ & & & \\
\hline \multicolumn{16}{|l|}{$\begin{array}{l}\text { Work \& economic } \\
\text { impacts }\end{array}$} \\
\hline Work disability & & & $\checkmark$ & & $\checkmark$ & $\checkmark$ & & & & $\checkmark^{*}$ & & $\checkmark^{*}$ & & & $\checkmark$ \\
\hline Economic impact & & & $\checkmark$ & & $\checkmark$ & $\checkmark$ & & & & & & & & & \\
\hline Total & $8 / 27$ & $11 / 27$ & $9 / 27$ & $5 / 27$ & $10 / 27$ & $12 / 27$ & $4 / 27$ & $6 / 27$ & $8 / 27$ & $8 / 27$ & $1 / 27$ & $7 / 27$ & $2 / 27$ & $1 / 27$ & $2 / 27$ \\
\hline
\end{tabular}

SLAQ - Systemic Lupus Activity Questionnaire, SF-36v2 - Short Form [36] Health Survey, EQ-5D - EuroQol 5-Dimensions, FACIT-Fatigue - Functional Assessment of Chronic IIIness Therapy, MFI - Multidimensional Fatigue Inventory, MAF - Multidimensional Assessment of Fatigue, MGQ - McGill Pain Scale, BPI - Brief Pain Inventory, BDI - Beck Depression Inventory, HADS - Hospital Anxiety and Depression Scale, WPAl:Lupus - Work Productivity and Activity Impairment Questionnaire: Lupus.

The following symptoms were identified as important in the literature review, but are not measured by current PROs: flu-like symptoms, dry mouth, skin rash, speech problems, vision sensitivity to bright lights,

sensitivity to hot/cold temperatures, reduced hand grip, haematological abnormalities, sleep related respiratory and movement problems ${ }^{\$}$ PRO measure has documented evidence of qualitative research with patients with SLE during item generation "Result valid for both the EQ-5D-3L and EQ-5D-5L *Concept assessed only as a fatigue related impact (p) Concept partially covered by one or more items. 
Table 3 Content and face validity of each patient-reported outcome measure

\begin{tabular}{|c|c|c|c|c|}
\hline PRO Instrument & $\begin{array}{l}\text { Content and face validity evaluated } \\
\text { with SLE patients using cognitive } \\
\text { debriefing methodology }\end{array}$ & Item wording acceptable & $\begin{array}{l}\text { Recall period acceptable for } \\
\text { patient population }\end{array}$ & $\begin{array}{l}\text { Response options } \\
\text { acceptable }\end{array}$ \\
\hline \multicolumn{5}{|l|}{ SLE-specific HRQoL } \\
\hline SLAQ & $x$ & $\checkmark$ & $x$ & $\checkmark$ \\
\hline LupusQoL & $\checkmark$ & $\checkmark$ & $x$ & $\checkmark$ \\
\hline LupusPRO & $\checkmark$ & $\checkmark$ & $x$ & $\checkmark$ \\
\hline L-QoL & $\checkmark$ & $\checkmark$ & $\checkmark$ & $\checkmark$ \\
\hline SLEQOL & $x$ & $\boldsymbol{x}$ 'Fatigue' not defined & $\checkmark$ & $\boldsymbol{x}$ Confusing \\
\hline \multicolumn{5}{|l|}{ Generic HRQoL } \\
\hline SF-36v2 & $x$ & $\checkmark$ & $x$ & $\checkmark$ \\
\hline$E Q-5 D^{\#}$ & $x$ & $\checkmark$ & $\checkmark$ & $\checkmark$ \\
\hline \multicolumn{5}{|l|}{ Fatigue } \\
\hline FACIT-Fatigue & $x$ & $\checkmark$ & $\checkmark$ & $\checkmark$ \\
\hline MFI & $x$ & $\checkmark$ & $\boldsymbol{x}$ 'Lately' too vague & $\boldsymbol{x}$ Confusing \\
\hline MAF & $x$ & $\boldsymbol{x}$ 'Fatigue' not defined & $\checkmark$ & $\boldsymbol{x}$ Confusing \\
\hline \multicolumn{5}{|l|}{ Pain } \\
\hline MPQ & $x$ & $\boldsymbol{x}$ Complex terms used & $\checkmark$ & $\boldsymbol{x}$ Complex terms used \\
\hline BPI-SF & $x$ & $\checkmark$ & $\boldsymbol{x}$ Some items don't specify recall & $\checkmark$ \\
\hline \multicolumn{5}{|l|}{ Depression } \\
\hline $\mathrm{BDI}$ & $x$ & $\boldsymbol{x}$ No question wording & $x$ None specified & $\boldsymbol{x}$ Lengthily \\
\hline HADS & $x$ & $\checkmark$ & $\checkmark$ & $\checkmark$ \\
\hline \multicolumn{5}{|l|}{ Work productivity } \\
\hline WPAI:Lupus & $x$ & $\boldsymbol{x}$ Some complex terms used & $\checkmark$ & $\checkmark$ \\
\hline
\end{tabular}

SLAQ - Systemic Lupus Activity Questionnaire, SF-36v2 - Short Form [36] Health Survey, EQ-5D - EuroQol 5-Dimensions, FACIT-Fatigue - Functional Assessment of Chronic Illness Therapy, MFI - Multidimensional Fatigue Inventory, MAF - Multidimensional Assessment of Fatigue, MGQ - McGill Pain Scale, BPI - Brief Pain Inventory, BDI - Beck Depression Inventory, HADS - Hospital Anxiety and Depression Scale, WPAl:Lupus - Work Productivity and Activity Impairment Questionnaire: Lupus.

"Result valid for both the EQ-5D-3L and EQ-5D-5L.

nine PROs had documented evidence of their measurement properties in patients with SLE. It is important to acknowledge that many recent randomised controlled trials (RCTs) in SLE have not incorporated the use of a patient global assessment of disease activity, thus making it difficult to determine minimal important differences (MIDs) for PRO measures. This may contribute to the lack of evidence pertaining to MIDs in SLE.

\section{Systemic lupus erythematosus specific health-related quality} of life measures

All five SLE-specific HRQOL measures reviewed in depth had sufficient evidence of internal consistency (i.e. $\alpha>0.7$ ) [40,47,50,52,55] (Table 4). The LupusQoL, L-QoL and SLEQOL had evidence of strong test-retest reliability (i.e. ICC > 0.7) [40,50], while the test-retest was shown for LupusPRO for only 7 out of its 11 domains [52]. The SLAQ had no evidence of test-retest reliability. Only the LupusQoL and $L-Q o L$ had sufficient evidence of validity for a SLE population [50]. While the SLAQ demonstrated construct validity [47], it had no evidence that it is capable of differentiating known groups, and the LupusPRO demonstrated high floor effects [52]. The LupusQoL and LupusPRO had no evidence of ability to detect change, while the SLAQ demonstrate a limited sensitivity to a change in health status but no evidence of responsiveness to changes to treatment [47].

\section{Generic health-related quality of life measures}

[79] Both of the generic HRQoL measures reviewed had sufficient evidence of test-retest reliability [75,80,81] and both demonstrated sufficient evidence of validity $[80,81]$ (Table 4).

The SF-36v2 has been validated in many different health conditions and is a widely used and accepted measure of HRQoL [80,81]. More importantly, in an SLE population, the $S F-36 v 2$ has demonstrated evidence of internal consistency reliability, concurrent validity and known groups validity [79]. The EQ-5D showed evidence of validity and an ability to detect change in patients with SLE [76] despite being commonly associated with ceiling and floor effects [82]. Of note, the SF36v2 is able to detect change in many conditions, including rheumatoid arthritis $[80,81]$ and more recently, distribution and anchor-based 
Table 4 Psychometric properties of patient-reported outcome measures in patients with SLE

\begin{tabular}{|c|c|c|c|c|c|c|c|}
\hline \multirow[t]{2}{*}{ Instrument } & \multirow{2}{*}{$\begin{array}{l}\text { Psychometrically } \\
\text { validated in a SLE } \\
\text { population }\end{array}$} & \multicolumn{2}{|l|}{ Reliability } & \multicolumn{3}{|l|}{ Validity } & \multirow{2}{*}{$\begin{array}{l}\text { Ability to } \\
\text { detect change }\end{array}$} \\
\hline & & $\begin{array}{l}\text { Internal consistency } \\
\text { (Cronbach's a) }\end{array}$ & Test-retest (ICC) & $\begin{array}{l}\text { Construct } \\
\text { validity }\end{array}$ & $\begin{array}{l}\text { Known } \\
\text { groups } \\
\text { validity }\end{array}$ & $\begin{array}{l}\text { Concurrent } \\
\text { validity }\end{array}$ & \\
\hline$\overline{S L A Q}$ & $\checkmark[47,78]$ & $\checkmark(0.87)[47]$ & - & $\checkmark[47,50]$ & - & $\checkmark[78]$ & $\checkmark[47]$ \\
\hline LupusQoL & $\checkmark[50]$ & $\checkmark(>0.70)[50]$ & $\checkmark(0.72-0.93)[50]$ & $\checkmark[50]$ & $\checkmark[50]$ & $\checkmark[50]$ & - \\
\hline LupusPRO & $\checkmark[52,76]$ & $\checkmark(0.72-0.94)[52]$ & $\begin{array}{l}\checkmark \text { (>0.70, except for } \\
3 \text { domains) [52] }\end{array}$ & $\begin{array}{l}\boldsymbol{x} \text { (High floor } \\
\text { effects) [52] - }\end{array}$ & $\checkmark[52,76]$ & $\checkmark[52]$ & - \\
\hline L-QoL & $\checkmark[40]$ & $\checkmark(0.92)[40]$ & $\checkmark(0.92)[40]$ & - & $\checkmark[40]$ & $\checkmark[40]$ & - \\
\hline SLEQOL & $\checkmark[55]$ & $\checkmark(0.95)[55]$ & $\checkmark(0.83)[55]$ & $\begin{array}{l}\boldsymbol{x} \text { (High floor } \\
\text { effects) [55] }\end{array}$ & - & Partial [55] & Partial [55] \\
\hline SF-36V2 & $x$ & Partial $(>0.70)[80,81]$ & Partial $[80,81]$ & Partial $[80,81]$ & Partial $[80,81]$ & Partial $[80,81]$. & $\begin{array}{l}\boldsymbol{x} \text { (for SLE) }[55,60] \\
\text { Partial }[80]\end{array}$ \\
\hline EQ-5D & $\checkmark[75]$ & - & $\begin{array}{l}\text { EQ-5D Index: Partial } \\
\text { (0.89) [75] EQ-5D } \\
\text { VAS: Partial (0.77) [75] }\end{array}$ & $\boldsymbol{x}[82]$ & $\checkmark[76]$ & $\checkmark[76]$ & $\checkmark[76]$ \\
\hline FACIT-Fatigue & $\checkmark[77]$ & $\checkmark(>0.95)[77]$ & Partial (0.95) [83] & - & $\checkmark[77]$ & $\checkmark[77]$ & $\checkmark[77]$ \\
\hline MFI & $x$ & Partial (0-68-0.89) [84] & - & Partial $[84,85]$ । & Partial $[84,86]$ & Partial [84] & Partial [87] \\
\hline MAF & $x$ & Partial (0.93) [68] & Partial (0.87) [88] & Partial [89] & Partial [90] & Partial [68] & Partial [91] \\
\hline MPQ & $x$ & Partial (a not provided) [69] & Partial $(r=>0.70)[69,92]$ & - & - & Partial [93] & Partial [94] \\
\hline BPI-SF & $x$ & Partial (0.80-0.92) [95] & Partial (0.83-0.88) [96] & Partial $[95,97,98]$ & Partial $[95,99]$ & Partial [99] & Partial $[100,101]$ \\
\hline BDI & $x$ & Partial (0.81) [102] & Partial (0.93) [102] & Partial $[102,103]$ & Partial $[102,103]$ & Partial [102] & - \\
\hline HADS & $x$ & $\begin{array}{l}\text { Partial (0.83, Anxiety sub-scale; } \\
0.82 \text {, Depression sub-scale) [104] }\end{array}$ & $\begin{array}{l}\text { Partial (0.84-0.85 for both } \\
\text { sub-scales) [105] }\end{array}$ & Partial $[73,104]$ & Partial [105] & Partial $[104,106]$ & Partial [105] \\
\hline WPAl:Lupus & $x$ & - & Partial (Pearson's: 0.71-0.75) [74] & - & Partial [107] & Partial [108] & Partial [107] \\
\hline
\end{tabular}


estimates suggest MIDs of approximately 3-6 points in an SLE population [79].

\section{Fatigue measures}

Of the fatigue measures, the FACIT-Fatigue demonstrated the strongest evidence of internal consistency reliability, known groups validity, concurrent validity, ability to detect change in a SLE population [77] (Table 4) and testretest reliability in psoriatic arthritis [83]. Furthermore, the FACIT-Fatigue has shown strong evidence of internal consistency reliability and known groups validity, with an MID of 3-4 points in rheumatoid arthritis [91]. The $M F I$ and $M A F$ had sufficient evidence of internal consistency $[68,84]$, though Cronbach's $\alpha$ for one of the $M F I$ domains was below 0.7 [84], and the $M A F$ had evidence of testretest reliability (in cancer) [88]. While not validated in a SLE population, the $M F I$ and $M A F$ had sufficient evidence of validity and an ability to detect for Sjögren's syndrome and rheumatoid arthritis (other autoimmune inflammatory conditions) $[68,84,86,89,90]$ but evidence of the ability of the $M A F$ to detect change was limited to cancer patients [87].

\section{Pain measures}

In terms of the pain items, neither the BPI-SF nor MPQ have been validated in SLE (Table 4). In other conditions, the BPI-SF demonstrated the strongest evidence of both internal consistency $(\alpha>0.7)$ and test-retest reliability $(\mathrm{ICC}>0.7)[95,96]$. The $M P Q$ had sufficient evidence of test-retest reliability also [69,92] but only provided partial evidence of internal consistency [69]. The BPI-SF had acceptable evidence of validity [95,97-99]. In contrast, the $M P Q$ had evidence of concurrent validity only [93]. The MPQ and BPI-SF demonstrated an ability to detect changes, with both providing evidence of responsiveness to treatment in musculoskeletal pain (MPQ) [94], cancer and rheumatoid arthritis patients (BPI-SF) $[100,101]$.

\section{Depression measures}

Neither the BDI nor HADS have been validated in SLE. However, both measures have evidence of reliability in other conditions $[102,104,105]$ (Table 4). Both measures have sufficient evidence of validity in the general population and psychiatric patients [73,102-106], though the construct validity of the $B D I$ varies, with the number of factors ranging from three to seven depending on the disease [102]. Of the two depression measures, only the $H A D S$ provides evidence of ability to detect change in response to intervention in different diseases, including depression, neurotic disorder, cancer and heart disease [105].

\section{Work productivity measure}

There is no documented evidence of the psychometric properties of the WPAI:Lupus in SLE, though item content in the general health version (WPAI:GH) is highly consistent with the 'specific health problem' version of the measure (WPAI:SHP) [109]. The content and item wording of the WPAI:GH and the WPAI:SHP is the same, with the exception of the term 'general health' in the WPAI: $G H$, which is replaced with the relevant disease. For the WPAI:Lupus, 'general health' is replaced with 'lupus'. Therefore, the validity of the WPAI:Lupus can be partially demonstrated by acceptable concurrent and known groups validity of the general health version of the measure (WPAI:GH) in the general population [74] and in rheumatoid arthritis [108]. The WPAI:GH also had evidence of test-retest reliability in rheumatoid arthritis [74] but none of internal consistency. Moreover, the ankylosing spondylitis-specific WPAI:SpA has shown known groups validity and responsiveness to treatment of ankylosing spondylitis [107].

\section{Discussion}

To understand the value of therapies for SLE from the patient-perspective, PRO measures should be included in clinical trials in conjunction with well-established clinical assessments. The selection of suitable measures to assess SLE-related symptoms and impacts in clinical trials requires careful consideration [14,15]. This study therefore sought to develop a conceptual model of the key symptoms and impacts associated with SLE to help support identification of suitable endpoints for clinical trials in SLE $[14,15]$. The model also aimed to integrate the economic burden of SLE to patients, health care providers and the wider society.

The key patient-reported concepts identified within the model were fatigue, pain, cognition, daily activities, emotional well-being, physical/social functioning and work productivity. The subjective nature of many SLE symptoms and impacts requires accurate and reliable measurement of these symptoms based on patient self-report. In light of this, our study also sought to review and evaluate the face and content validity and psychometric properties of PROs that may be appropriate for use in a SLE population. To our knowledge, this is the first comprehensive review of PROs for the whole range of key symptoms and impacts experienced specifically by patients with SLE. The American College of Rheumatology conducted a review to recommend measures for inclusion in SLE trials [34], but this was limited to the evaluation of fatigue. In a review of outcome measures in SLE clinical trials, Strand et al. [54] included a brief summary of the measurement properties of a small number of selected HRQoL measures used previously in SLE trials, but this review did not include evaluation of face and content validity. 
The current review showed that the LupusQoL, SLEQOL, SF-36v2, FACIT-Fatigue and BPI-SF demonstrated face and content validity and were psychometrically strong as measures of the key concepts identified in the conceptual model. The FACIT-Fatigue and BPI-SF appeared to be the strongest instruments. In addition, the generic $S F-36 v 2$ and EQ-5D measures are widely used in trials with patients with SLE and are recognised and accepted by clinical, patient, regulatory, reimbursement and academic communities.

A recent qualitative study involving SLE patients concluded that the FACIT-Fatigue is a relevant measure of fatigue in SLE [28]. Furthermore, the psychometric properties of the FACIT-Fatigue in an SLE population are well documented [77]. In contrast, the American College of Rheumatology study from 2007 suggest the Fatigue Severity Scale (FSS) as a measure of fatigue in SLE [34]. However, our review questions the lack of SLE patient involvement in the initial development of the FSS; and the lack of supporting evidence of its face and content validity. Furthermore, the psychometric properties of the FSS have been assessed but in a limited number of patients with SLE $[110,111]$. Indeed, of all the PRO measures reviewed, only three Lupus-specific measures (LupusQoL, LupusPRO and $L-Q o L)$ have documented evidence of qualitative input from patients with SLE.

Important in the measurement of SLE is to acknowledge that patients may experience many symptom-free days, followed by a severe flare. Flares are likely to impact patients' health-related quality of life [7,10], as well as having a wider society and economic impact [45]. For example, patients with flares incur higher direct and indirect costs compared with those without flares [45]. Therefore, PRO measurement of the impact of flares may be considered in future clinical trials in patients with SLE in addition to clinical outcome assessments $[14,15]$. Despite this, no PRO measures were identified which target the impact of flares on humanistic burden. In addition, SLE often involves day-to-day symptom fluctuations due to these flares, thus the recall period of the measurement instrument is also an important consideration. PROs with shorter recall periods may underestimate symptom burden and may place undue demand on patients; however, longer recall period may not allow for reliable symptom and impact reporting.

Whilst the validity of this literature review is strengthened by the inclusion of qualitative and quantitative studies, with the review of PRO measures conducted in accordance with regulatory guidelines [11,12,23], there are inherent limitations. Firstly, an assessment of the quality of the studies identified from the literature search was not conducted, so as not to limit our search. The review was however intended to be as inclusive and wideranging as possible to capture all of the key concepts for the development of the conceptual model and to ensure that atypical symptoms were not missed. Secondly, after key SLE symptoms and impacts in the conceptual model were identified, PROs were selected for in-depth review on the basis of measurement of those fundamental symptoms and impacts. PRO measures of other symptoms of SLE not reported in the conceptual model were thus deprioritised and therefore not included in the in-depth review. Nevertheless, PRO measures for some key concepts identified in the model (for example, skin manifestations of the disease, impact of flares and treatment satisfaction) were either not identified from the literature search, or no PRO has been used to measure these concepts in SLE. This represents a gap in knowledge which may benefit from further research.

PROs are acknowledged as complementary to more objective measures and are being incorporated more frequently into clinical trials and clinical practice [112]. The recognition and measurement of disease experience from the patient's perspective is an important factor for SLE clinical trial design and health care decision makers. The results of the present study, demonstrating the suitability of PROs for use in clinical trials of SLE within the guidance provided by the FDA and EMA $[11,12,14,15]$, can hopefully be of benefit to clinical research within SLE.

\section{Conclusion}

SLE is a condition associated with high unmet need and considerable burden to patients, as demonstrated by the conceptual model presented in this paper. This review highlights the existing patient-reported measures of HRQoL, SLE signs and symptoms and work productivity that demonstrate appropriate content and face validity and are psychometrically adequate for a population of patients with SLE, and as a result such measures may be suitable for use in SLE clinical trials.

\section{Abbreviations}

BDI: Beck depression inventory; BPI-SF: Brief Pain Inventory - Short Form; EMA: European Medicines Agency; FDA: Food and Drug Administration; HRQoL: Health-related quality of life; IQWIG: Germany, Institute for Quality and Efficiency in Healthcare; LN: Lupus Nephritis; MPQ: McGill Pain

Questionnaire; MAF: Multidimensional Assessment of Fatigue; NICE: UK, National Institute of Health and Clinical Excellence; PROs: Patient-reported Outcomes; SLE: Systemic lupus erythematosus; FACIT-Fatigue: The Functional Assessment of Chronic Illness Therapy - Fatigue Scale; HADS: The Hospital Anxiety and Depression Scale; WPAl:Lupus: Work Productivity and Activity Impairment Questionnaire: Lupus.

\section{Competing interests}

The study was funded by Novo Nordisk A/S, Denmark and conducted by Adelphi Values. LHo, LHu, LHe, CP and HK are employees of Adelphi Values (or were employees at the time the research was conducted). LHø, MS-L, and $\mathrm{BBH}$ are employees of Novo Nordisk A/S.

\section{Authors' contributions}

$\mathrm{LHo}, \mathrm{LHu}, \mathrm{LHe}, \mathrm{CP}$ and HK participated in the study conception and design, analysis and interpretation of literature, development of the conceptual model, and reviewed and approved the manuscript. LHø, MS-L, and BBH participated in the study conception and design, analysis and interpretation, 
reviewed and approved the final version of the manuscript. All authors read and approved the final manuscript.

\section{Acknowledgements}

Ben Rousseau, Steven Blackburn, and Mark Forshaw, all of Adelphi Values, provided medical writing support for this article.

\section{Author details}

${ }^{1}$ Adelphi Values, Adelphi Mill, Bollington, Macclesfield, Cheshire SK10 5JB, UK.

${ }^{2}$ Abacus International, Manchester One, Manchester M1 3LD, UK. ${ }^{3}$ The University of Manchester, Oxford Road, Manchester M13 9PL, UK. ${ }^{4}$ Novo Nordisk A/S, Novo Allé 1, 2880 Bagsvaerd, Denmark.

Received: 10 March 2014 Accepted: 8 July 2014

Published: 22 July 2014

\section{References}

1. Jakes RW, Bae SC, Louthrenoo W, Mok CC, Navarra SV, Kwon N: Systematic review of the epidemiology of systemic lupus erythematosus in the Asia-Pacific region: prevalence, incidence, clinical features, and mortality. Arthritis Care Res 2012, 64:159-168.

2. Danchenko N, Satia JA, Anthony MS: Epidemiology of systemic lupus erythematosus: a comparison of worldwide disease burden. Lupus 2006, 15:308-318.

3. Chakravarty EF, Bush TM, Manzi S, Clarke AE, Ward MM: Prevalence of adult systemic lupus erythematosus in California and Pennsylvania in 2000: estimates obtained using hospitalization data. Arthritis Rheum 2007, 56:2092-2094.

4. Borchers AT, Naguwa SM, Shoenfeld Y, Gershwin ME: The geoepidemiology of systemic lupus erythematosus [abstract]. Autoimmun Rev 2010, 9:A277-A287.

5. Zhu TY, Tam LS, Li EK: Cost-of-illness studies in systemic lupus erythematosus: a systematic review. Arthritis Care Res (Hoboken) 2011, 63:751-760

6. Manson JJ, Rahman A: Systemic lupus erythematosus. Orphanet J Rare Dis 2006, 1:6.

7. Ruperto N, Hanrahan LM, Alarcon GS, Belmont HM, Brey RL, Brunetta P, Buyon JP, Costner MI, Cronin ME, Dooley MA, Filocamo G, Fiorentino D, Fortin PR, Franks AG Jr, Gilkeson G, Ginzler E, Gordon C, Grossman J, Hahn B, Isenberg DA, Kalunian KC, Petri M, Sammaritano L, Sánchez-Guerrero J, Sontheimer RD, Strand V, Urowitz M, von Feldt JM, Werth VP, Merrill JT: International consensus for a definition of disease flare in lupus. Lupus 2011, 20:453-462.

8. Lahita RG: Systemic Lupus Erythematosus. London: Elsevier; 2004

9. Lupus: Statistics on Lupus. Foundation of America. [http://www.lupus.org/ about/statistics-on-lupus]

10. Jolly M, Pickard AS, Wilke C, Mikolaitis RA, Teh LS, McElhone K, Fogg L, Block J: Lupus-specific health outcome measure for US patients: the LupusQoL-US version. Ann Rheum Dis 2010, 69:29-33.

11. Food \& Drug Administration: Guidance For Industry: Patient-Reported Outcome Measures: Use In Medical Product Development To Support Labelling Claims; 2009. http://www.fda.gov/downloads/Drugs/Guidances/ UCM193282.pdf

12. European Medicines Agency: Reflection Paper on the Regulatory Guidance for the use of Health-Related Quality of Life (HRQL) Measures in the Evaluation of Medicinal Products; 2005. http://www.ispor.org/workpaper/emea-hrqlguidance.pdf

13. Department of Health: Equity and Excellence: Liberating the NHS; 2010. https://www.gov.uk/government/uploads/system/uploads/attachment_ data/file/213823/dh_117794.pdf.

14. Food \& Drug Administration: Guidance for Industry: Systemic Lupus Erythematosus - Developing Medical Products for Treatment; 2010 http://www.fda.gov/downloads/Drugs/GuidanceComplianceRegulatory Information/Guidances/ucm072063.pdf.

15. European Medicines Agency: Guideline on Clinical Investigation of Medicinal Products for the Treatment of Systemic Lupus Erythematosus, Cutaneous Lupus and Lupus Nephritis (Draft); 2013. http://www.ema.europa.eu/docs/en_GB/ document_library/Scientific_guideline/2013/03/WC500139615.pdf.

16. Strand V, Gladman D, Isenberg D, Petri M, Smolen J, Tugwell P: Outcome measures to be used in clinical trials in systemic lupus erythematosus. J Rheumatol 1999, 26:490-497.
17. Smolen JS, Strand V, Cardiel M, Edworthy S, Furst D, Gladman D, Gordon C, Isenberg DA, Klippel JH, Petri M, Simon L, Tugwell P, Wolfe F: Randomized clinical trials and longitudinal observational studies in systemic lupus erythematosus: consensus on a preliminary core set of outcome domains. J Rheumatol 1999, 26:504-507.

18. Moher D, Liberati A, Tetzlaff J, Altman DG: Preferred reporting items for systematic reviews and meta-analyses: the PRISMA statement [abstract]. BMJ 2009, 339:b2535.

19. Systematic Reviews: CRD's guidance for undertaking systematic reviews in health care. http://www.york.ac.uk/inst/crd/pdf/Systematic_Reviews.pdf.

20. Earp JA, Ennett ST: Conceptual models for health education research and practice. Health Educ Res 1991, 6:163-171.

21. Rothman ML, Beltran P, Cappelleri JC, Lipscomb J, Teschendorf B, the Mayo/F. D. A. Patient-Reported Outcomes Consensus Meeting Group: Patient-reported outcomes: conceptual issues. Value Health 2007, 10:S66-S75.

22. Gallop K, Nixon A, Swinburn P, Sterling KL, Naegeli AN, Silk ME: Development of a conceptual model of health-related quality of life for systemic lupus erythematosus (SLE) from the patients' perspective. Lupus 2012, 21:934-943.

23. Mokkink L, Terwee C, Patrick D, Alonso J, Stratford P, Knol D, Bouter L, Vet H: The COSMIN checklist for assessing the methodological quality of studies on measurement properties of health status measurement instruments: an international Delphi study. Qual Life Res 2010, 19:539-549.

24. Beckerman NL: Living with lupus: a qualitative report. Soc Work Health Care 2011, 50:330-343

25. McElhone K, Abbott J, Gray J, Williams A, Teh LS: Patient perspective of systemic lupus erythematosus in relation to health-related quality of life concepts: a qualitative study. Lupus 2010, 19:1640-1647.

26. Robinson J, Aguilar D, Schoenwetter M, Dubois R, Russak S, Ramsey-Goldman R, Navarra S, Hsu B, Revicki D, Cella D, Rapaport MH, Renahan K, Ress R, Wallace D, Weisman M: Impact of systemic lupus erythematosus on health, family, and work: the patient perspective. Arthritis Care Res 2010, 62:266-273.

27. Mattsson M, Moller B, Stamm T, Gard G, Bostrom C: Uncertainty and opportunities in patients with established systemic Lupus Erythematosus: a qualitative study. Musculoskeletal Care 2012, 10:1-12.

28. Kosinski M, Gajria K, Fernandes AW, Cella D: Qualitative validation of the FACIT-fatigue scale in systemic lupus erythematosus. Lupus 2013, 22:422-430.

29. Schneider M, Schmeding A, Carnarius H, Ager M, McWade V: Systemic lupus erythematosus (SLE): understanding the burden. Value Health 2010, 13:A470.

30. Yee CS, McElhone K, Teh LS, Gordon C: Assessment of disease activity and quality of life in systemic lupus erythematosus - New aspects. Best Pract Res Clin Rheumatol 2009, 23:457-467.

31. Aberer E: Epidemiologic, socioeconomic and psychosocial aspects in lupus erythematosus. Lupus 2010, 19:1118-1124.

32. Strand V, Galateanu C, Pushparajah DS, Nikai E, Sayers J, Wood R, van Vollenhoven RF: Limitations of current treatments for systemic lupus erythematosus: a patient and physician survey. Lupus 2013, 22:819-826.

33. Pettersson S, Lovgren M, Eriksson LE, Moberg C, Svenungsson E, Gunnarsson I, Henriksson EW: An exploration of patient-reported symptoms in systemic lupus erythematosus and the relationship to health-related quality of life. Scand J Rheumatol 2012, 41:383-390.

34. Ad Hoc Committee on Systemic Lupus Erythematosus Response Criteria for Fatigue: Measurement of fatigue in systemic lupus erythematosus: a systematic review. Arthritis Care Res 2007, 57:1348-1357.

35. Cleanthous S, Tyagi M, Isenberg DA, Newman SP: What do we know about self-reported fatigue in systemic lupus erythematosus? Lupus 2012, 21:465-476.

36. Ramsey-Goldman R, Rothrock N: Fatigue in systemic lupus erythematosus and rheumatoid arthritis. PM\&R 2010, 2:384-392.

37. Danoff-Burg S, Friedberg F: Unmet needs of patients with systemic lupus erythematosus. Behav Med 2009, 35:5-13.

38. Yazdany J, Yelin E: Health-related quality of life and employment among persons with systemic Lupus Erythematosus. Rheum Dis Clin North Am 2010, 36:15-32.

39. Robinson M, Sheets CS, Currie LM: Systemic lupus erythematosus: a genetic review for advanced practice nurses. J Am Acad Nurse Pract 2011, 23:629-637.

40. Doward LC, McKenna SP, Whalley D, Tennant A, Griffiths B, Emery P, Veale DJ: The development of the L-QoL: a quality-of-life instrument specific to systemic lupus erythematosus. Ann Rheum Dis 2009, 68:196-200. 
41. Johnsson PM, Sandqvist G, Bengtsson A, Nived O: Hand function and performance of daily activities in systemic lupus erythematosus. Arthritis Rheum 2008, 59:1432-1438.

42. Carls G, Li T, Panopalis P, Wang S, Mell AG, Gibson TB, Goetzel RZ: Direct and indirect costs to employers of patients with systemic lupus erythematosus with and without nephritis. J Occup Environ Med 2009, 51:66-79.

43. Zhu TY, Tam LS, Li EK: The socioeconomic burden of systemic lupus erythematosus: state-of-the-art and prospects. Expert Rev Pharmacoecon Outcomes Res 2012, 12:53-69.

44. Yelin E, Katz P: Introduction to special section: cost and social and psychological impact of rheumatic diseases. Arthritis Rheum 2008, 59:457.

45. Zhu TY, Tam LS, Lee WWY, Lee KKC, Li EK: The impact of flare on disease costs of patients with systemic lupus erythematosus. Arthritis Rheum 2009, 61:1159-1167.

46. Aghdassi E, Zhang W, St. Pierre Y, Clarke AE, Morrison S, Peeva V, Landolt-Marticorena C, Su J, Reich H, Scholey J, Herzenberg A, Pope JE, Peschken C, Lunnet Canios I, Wither JE, Fortin PR: Healthcare cost and loss of productivity in a Canadian population of patients with and without lupus nephritis. J Rheumatol 2011, 38:658-666.

47. Yazdany J, Yelin EH, Panopalis P, Trupin L, Julian L, Katz PP: Validation of the systemic lupus erythematosus activity questionnaire in a large observational cohort. Arthritis Rheum 2008, 59:136-143.

48. Askanase AD, Castrejon I, Pincus T: Quantitative data for care of patients with systemic lupus erythematosus in usual clinical settings: a patient multidimensional health assessment questionnaire and physician estimate of noninflammatory symptoms. J Rheumatol 2011, 38:1309-1316.

49. Moldovan I, Katsaros E, Carr FN, Cooray D, Torralba K, Shinada S, Ishimori ML, Jolly M, Wallace DJ, Weisman MH, Nicassio PM: The Patient Reported Outcomes in Lupus (PATROL) study: role of depression in health-related quality of life in a Southern California lupus cohort. Lupus 2011, 20:1285-1292.

50. McElhone K, Abbott J, Shelmerdine J, Bruce IN, Ahmad Y, Gordon C, Peers K, Isenberg D, Ferenkeh-Koroma A, Griffiths B, Akil M, Maddison P, Teh LS: Development and validation of a disease-specific health-related quality of life measure, the LupusQoL, for adults with systemic lupus erythematosus. Arthritis Rheum 2007, 57:972-979.

51. Strand V, Chu AD: Generic versus disease-specific measures of health-related quality of life in systemic lupus erythematosus. J Rheumatol 2011, 38:1821-1823.

52. Jolly M, Pickard AS, Block JA, Kumar RB, Mikolaitis RA, Wilke CT, Rodby RA, Fogg L, Sequeira W, Utset TO, Cash TF, Moldovan I, Katsaros E, Nicassio P, Ishimori ML, Kosinsky M, Merrill JT, Weisman MH, Wallace DJ: Disease-specific patient reported Outcome tools for systemic lupus erythematosus. Semin Arthritis Rheum 2012, 42:56-65.

53. Jolly M, Garris CP, Jhingran PM, Mikolaitis RA, Dennis G, Wallace DJ, Clarke A, Dooley MA, Parke A, Strand V, Alárcon GS, Kosinski M: Development of the lupus impact tracker: a tool for patients and physicians to assess and monitor the impact of systemic lupus erythematosus (SLE). Arthritis Care Res (Hoboken) 2011, 14:A65-A66.

54. Strand V, Chu AD: Measuring outcomes in systemic lupus erythematosus clinical trials. Expert Rev Pharmacoecon Outcomes Res 2011, 11:455-468.

55. Leong KP, Kong KO, Thong BYH, Koh ET, Lian TY, Teh CL, Cheng YK, Chng HH, Badsha H, Law WG, Lau TC, Chew LC, Ho HJ, Pong LY, Hoi LS, Sangeetha N, Chan SP, Howe HS: Development and preliminary validation of a systemic lupus erythematosus-specific quality-of-life instrument (SLEQOL). Rheumatology 2005, 44:1267-1276.

56. Ware JE Jr, Sherbourne CD: The MOS 36-item short-form health survey (SF-36). I. Conceptual framework and item selection. Med Care 1992, 30:473-483

57. Almehed $\mathrm{K}$, Carlsten H, Forsblad-D'Elia H: Health-related quality of life in systemic lupus erythematosus and its association with disease and work disability. Scand J Rheumatol 2010, 39:58-62.

58. Benitha R, Tikly M: Functional disability and health-related quality of life in South Africans with rheumatoid arthritis and systemic lupus erythematosus. Clin Rheumatol 2007, 26:24-29.

59. Kulczycka L, Sysa-Jedrzejowska A, Robak E: Quality of life and satisfaction with life in SLE patients-the importance of clinical manifestations. Clin Rheumatol 2010, 29:991-997.

60. Kuriya B, Gladman DD, Ibañez D, Urowitz MB: Quality of life over time in patients with systemic lupus erythematosus. Arthritis Care Res 2008, 59:181-185.
61. Mok CC, Ho LY, Cheung MY, Yu KL, To CH: Effect of disease activity and damage on quality of life in patients with systemic lupus erythematosus: a 2-year prospective study. Scand J Rheumatol 2009, 38:121-127.

62. Sliem H, Tawfik G, Khalil KA, Ibrahim N: Pattern of systemic lupus erythematosus in Egyptian patients: the impact of disease activity on the quality of life. Pan Afr Med J 2010, 6:14.

63. Zhu TY, Tam LS, Lee WY, Lee KK, Li EK: Relationship between flare and health-related quality of life in patients with systemic lupus erythematosus. J Rheumatol 2010, 37:568-573.

64. The EuroQol Group: EuroQol-a new facility for the measurement of health-related quality of life. Health Policy 1990, 16:199-208.

65. Herdman M, Gudex C, Lloyd A, Janssen M, Kind P, Parkin D, Bonsel G, Badia $X$ : Development and preliminary testing of the new five-level version of EQ-5D (EQ-5D-5L). Qual Life Res 2011, 20:1727-1736.

66. Yellen SB, Cella DF, Webster K, Blendowski C, Kaplan E: Measuring fatigue and other anemia-related symptoms with the Functional Assessment of Cancer Therapy (FACT) measurement system. J Pain Symptom Manage 1997, 13:63-74.

67. Smets EM, Garssen B, Bonke B, De Haes JC: The Multidimensional Fatigue Inventory (MFI) psychometric qualities of an instrument to assess fatigue. J Psychosom Res 1995, 39:315-325.

68. Belza BL, Henke CJ, Yelin EH, Epstein WV, Gilliss CL: Correlates of fatigue in older adults with rheumatoid arthritis. Nurs Res 1993, 42:93-99.

69. Melzack R: The McGill Pain Questionnaire: major properties and scoring methods. Pain 1975, 1:277-299.

70. Ozel F, Argon G: The effects of fatigue and pain on daily life activities in systemic lupus erythematosus. 2011Abstracts from 10th Congress of the European Federation of Internal Medicine [abstract. Eur J Intern Med 2011, 22:570.

71. Cleeland CS, Ryan KM: Pain assessment: global use of the Brief Pain Inventory. Ann Acad Med Singapore 1994, 23:129-138.

72. Beck AT, Ward CH, Mendelson M, Mock J, Erbaugh J: An inventory for measuring depression. Arch Gen Psychiatry 1961, 4:561-571.

73. Zigmond AS, Snaith RP: The hospital anxiety and depression scale. Acta Psychiatr Scand 1983, 67:361-370.

74. Reilly MC, Zbrozek AS, Dukes EM: The validity and reproducibility of a work productivity and activity impairment instrument. Pharmacoeconomics 1993, 4:353-365.

75. Konig HH, Ulshofer A, Gregor M, von Tirpitz C, Reinshagen M, Adler G, Leidl R: Validation of the EuroQol questionnaire in patients with inflammatory bowel disease. Eur J Gastroenterol Hepatol 2002, 14:1205-1215.

76. Aggarwal R, Wilke CT, Pickard AS, Vats V, Mikolaitis R, Fogg L, Block JA, Jolly M: Psychometric properties of the EuroQol-5D and short form-6D in patients with systemic lupus erythematosus. J Rheumatol 2009, 36:1209-1216.

77. Lai JS, Beaumont JL, Ogale S, Brunetta P, Cella D: Validation of the functional assessment of chronic illness therapy-fatigue scale in patients with moderately to severely active systemic lupus erythematosus, participating in a clinical trial. J Rheumatol 2011, 38:672-679.

78. Karlson EW, Daltroy LH, Rivest C, Ramsey-Goldman R, Wright EA, Partridge AJ, Liang MH, Fortin PR: Validation of a Systemic Lupus Activity Questionnaire (SLAQ) for population studies. Lupus 2003, 12:280-286.

79. Beaumont JLL J, Cella D, Brunetta P, Ogale S: Validation of the SF-36 in Patients with Systemic Lupus Erythematosus (SLE). Arthritis Rheum 2009, 60:296.

80. Busija L, Pausenberger $E$, Haines TP, Haymes S, Buchbinder R, Osborne RH: Adult measures of general health and health-related quality of life: Medical Outcomes Study Short Form 36-Item (SF-36) and Short Form 12-Item (SF-12) Health Surveys, Nottingham Health Profile (NHP), Sickness Impact Profile (SIP), Medical Outcomes Study Short Form 6D (SF-6D), Health Utilities Index Mark 3 (HUI3), Quality of Well-Being Scale (QWB), and Assessment of Quality of Life (AQOL) [abstract]. Arthritis Care Res 2011, 63:S383-S412.

81. QualityMetric Inc.: User's Manual for the SF-36v2 Health Survey. 3rd edition; 2011. http://www.qualitymetric.com/WhatWeDo/ManualsUserGuides/ UsersManualfortheSF36v2HealthSurvey/tabid/328/Default.aspx.

82. Gignac MAM, Cao X, McAlpine J, Badley EM: Measures of disability: Arthritis Impact Measurement Scales 2 (AIMS2), Arthritis Impact Measurement Scales 2-Short Form (AIMS2-SF), The Organization for Economic Cooperation and Development (OECD) Long-Term Disability (LTD) Questionnaire, EQ-5D, World Health Organization Disability Assessment Schedule II (WHODASII), Late-Life Function and Disability 
Instrument (LLFDI), and Late-Life Function and Disability Instrument-Abbreviated Version (LLFDI-Abbreviated) [abstract]. Arthritis Care Res 2011, 63:S308-\$324.

83. Chandran V, Bhella S, Schentag C, Gladman DD: Functional assessment of chronic illness therapy-fatigue scale is valid in patients with psoriatic arthritis. Ann Rheum Dis 2007, 66:936-939.

84. Goodchild CE, Treharne GJ, Booth DA, Kitas GD, Bowman SJ: Measuring fatigue among women with Sjogren's syndrome or rheumatoid arthritis: a comparison of the Profile of Fatigue (ProF) and the Multidimensional Fatigue Inventory (MFI). Musculoskeletal Care 2008, 6:31-48.

85. Lin J-M, Brimmer D, Maloney E, Nyarko E, BeLue R, Reeves W: Further validation of the Multidimensional Fatigue Inventory in a US adult population sample. Popul Health Metrics 2009, 7:18.

86. Barendregt PJ, Visser MR, Smets EM, Tulen JH, van den Meiracker AH, Boomsma F, Markusse HM: Fatigue in primary Sjogren's syndrome. Ann Rheum Dis 1998, 57:291-295.

87. Smets E, Garssen B, Cull A, De Haes J: Application of the multidimensional fatigue inventory (MFI-20) in cancer patients receiving radiotherapy. $\mathrm{Br} J$ Cancer 1996, 73:241.

88. Meek PM, Nail LM, Barsevick A, Schwartz AL, Stephen S, Whitmer K, Beck SL, Jones LS, Walker BL: Psychometric Testing of Fatigue Instruments for Use With Cancer Patients. Nurs Res 2000, 49:181-190.

89. Wolfe F: Fatigue assessments in rheumatoid arthritis: comparative performance of visual analog scales and longer fatigue questionnaires in 7760 patients. Arthritis Rheumatol 2004, 31:1896-1902.

90. Jump RL, Fifield J, Tennen H, Reisine S, Giuliano AJ: History of affective disorder and the experience of fatigue in rheumatoid arthritis. Arthritis Care Res 2004, 51:239-245.

91. Cella D, Yount S, Sorensen M, Chartash E, Sengupta N, Grober J: Validation of the Functional Assessment of Chronic Illness Therapy Fatigue Scale relative to other instrumentation in patients with rheumatoid arthritis. J Rheumatol 2005, 32:811-819.

92. Roche PA, Klestov AC, Heim HM: Description of stable pain in rheumatoid arthritis: a 6 year study. Arthritis Rheumatol 2003, 30:1733-1738.

93. Creamer $P$, Lethbridge-Cejku M, Hochberg M: Determinants of pain severity in knee osteoarthritis: effect of demographic and psychosocial variables using 3 pain measures. Arthritis Rheumatol 1999, 26:1785.

94. Jenkinson C, Carroll D, Egerton M, Frankland T, McQuay H, Nagle C: Comparison of the sensitivity to change of long and short form pain measures. Qual Life Res 1995, 4:353-357.

95. Cleeland CS, Gonin R, Hatfield AK, Edmonson JH, Blum RH, Stewart JA, Pandya KJ: Pain and its treatment in outpatients with metastatic cancer. N Engl J Med 1994, 330:592-596.

96. Mendoza T, Mayne T, Rublee D, Cleeland C: Reliability and validity of a modified Brief Pain Inventory short form in patients with osteoarthritis. Eur J Pain 2006, 10:353-361.

97. Atkinson TM, Rosenfeld BD, Sit L, Mendoza TR, Fruscione M, Lavene D, Shaw M, Li Y, Hay J, Cleeland CS, Scher HI, Breitbart WS, Basch E: Using confirmatory factor analysis to evaluate construct validity of the Brief Pain Inventory (BPI). J Pain Symptom Manage 2011, 41:558-565.

98. Williams VSL, Smith MY, Fehnel SE: The validity and utility of the BPI interference measures for evaluating the impact of osteoarthritic pain. J Pain Symptom Manag 2006, 31:48-57.

99. Keller S, Bann CM, Dodd SL, Schein J, Mendoza TR, Cleeland CS: Validity of the brief pain inventory for use in documenting the outcomes of patients with noncancer pain. Clin J Pain 2004, 20:309-318.

100. Daut RL, Cleeland CS, Flannery RC: Development of the Wisconsin Brief Pain Questionnaire to assess pain in cancer and other diseases. Pain 1983, 17:197-210.

101. Mease PJ, Spaeth M, Clauw DJ, Arnold LM, Bradley LA, Russell IJ, Kajdasz DK, Walker DJ, Chappell AS: Estimation of minimum clinically important difference for pain in fibromyalgia. Arthritis Care Res 2011, 63:821-826.

102. Beck AT, Steer RA, Carbin MG: Psychometric properties of the Beck Depression Inventory: Twenty-five years of evaluation. Clin Psychol Rev 1988, 8:77-100.

103. Hiroe T, Kojima M, Yamamoto I, Nojima S, Kinoshita Y, Hashimoto N, Watanabe N, Maeda T, Furukawa TA: Gradations of clinical severity and sensitivity to change assessed with the Beck Depression Inventory-II in Japanese patients with depression. Psychiatry Res 2005, 135:229-235.
104. Bjelland I, Dahl AA, Haug TT, Neckelmann D: The validity of the Hospital Anxiety and Depression Scale: An updated literature review. J Psychosom Res 2002, 52:69-77.

105. Herrmann C: International experiences with the Hospital Anxiety and Depression Scale-A review of validation data and clinical results. J Psychosom Res 1997, 42:17-41.

106. Silverstone PH: Poor efficacy of the hospital anxiety and depression scale in the diagnosis of major depressive disorder in both medical and psychiatric patients. J Psychosom Res 1994, 38:441-450.

107. Reilly MC, Gooch KL, Wong RL, Kupper H, van der Heijde D: Validity, reliability and responsiveness of the Work Productivity and Activity Impairment Questionnaire in ankylosing spondylitis. Rheumatology (Oxford) 2010, 49:812-819.

108. Zhang W, Bansback N, Boonen A, Young A, Singh A, Anis A: Validity of the work productivity and activity impairment questionnaire - general health version in patients with rheumatoid arthritis [abstract]. Arthritis Res Ther 2010, 12:R177.

109. Tang R, Groshen SG, Piatek Cl, Desai BB, Pinski JK, Acosta F, Raghavan D, Dorff TB, Quinn DI: Sequential active chemotherapy schema in castration-resistant prostate cancer [abstract]. J Clin Oncol 2011, 29:e15191.

110. Krupp L, LaRocca N, Muir-Nash J, Steinberg A: The fatigue severity scale: Application to patients with multiple sclerosis and systemic lupus erythematosus. Arch Neurol 1989, 46:1121-1123.

111. Mattsson M, Moller B, Lundberg IE, Gard G, Bostrom C: Reliability and validity of the Fatigue Severity Scale in Swedish for patients with systemic lupus erythematosus. Scand J Rheumatol 2008, 37:269-277.

112. Refolo P, Minacori R, Mele V, Sacchini D, Spagnolo AG: Patient-reported outcomes (PROs): the significance of using humanistic measures in clinical trial and clinical practice. Eur Rev Med Pharmacol Sci 2012, 16:1319-1323

doi:10.1186/s12955-014-0116-

Cite this article as: Holloway et al:: Patient-reported outcome measures for systemic lupus erythematosus clinical trials: a review of content validity, face validity and psychometric performance. Health and Quality of Life Outcomes 2014 12:116.

\section{Submit your next manuscript to BioMed Central and take full advantage of:}

- Convenient online submission

- Thorough peer review

- No space constraints or color figure charges

- Immediate publication on acceptance

- Inclusion in PubMed, CAS, Scopus and Google Scholar

- Research which is freely available for redistribution 